\title{
Assessment of Combustor Working Environments
}

\author{
Leiyong Jiang and Andrew Corber \\ Aerospace Research, Gas Turbine Laboratory, The National Research Council of Canada, 1200 Montreal Road, M-10, Ottawa, \\ ON, Canada K1A 0R6
}

Correspondence should be addressed to Leiyong Jiang, leiyong.jiang@nrc-cnrc.gc.ca

Received 10 March 2012; Accepted 29 June 2012

Academic Editor: Victor Giurgiutiu

Copyright ( $\odot 2012$ L. Jiang and A. Corber. This is an open access article distributed under the Creative Commons Attribution License, which permits unrestricted use, distribution, and reproduction in any medium, provided the original work is properly cited.

\begin{abstract}
In order to assess the remaining life of gas turbine critical components, it is vital to accurately define the aerothermodynamic working environments and service histories. As a part of a major multidisciplinary collaboration program, a benchmark modeling on a practical gas turbine combustor is successfully carried out, and the two-phase, steady, turbulent, compressible, reacting flow fields at both cruise and takeoff are obtained. The results show the complicated flow features inside the combustor. The airflow over each flow element of the combustor can or liner is not evenly distributed, and considerable variations, $\pm 25 \%$, around the average values, are observed. It is more important to note that the temperatures at the combustor can and cooling wiggle strips vary significantly, which can significantly affect fatigue life of engine critical components. The present study suggests that to develop an adequate aerothermodynamics tool, it is necessary to carry out a further systematic study, including validation of numerical results, simulations at typical engine operating conditions, and development of simple correlations between engine operating conditions and component working environments. As an ultimate goal, the cost and time of gas turbine engine fleet management must be significantly reduced.
\end{abstract}

\section{Motivation}

It is a promising approach to assess the remaining life of gas turbine critical components, based on their service history (flight operating conditions and sensor readings), by applying aerothermodynamics, structural and material analysis models. It is consistent with condition-based maintenance $(\mathrm{CBM})$ of gas turbine engines, that is, maintenance actions would be performed only when they are required. As a result, the expense of maintenance/repair of an engine fleet can be reduced, the engine operation can be made more reliable, and service life can be extended. This approach has been investigated by researchers from various disciplines under a major collaboration program [1].

One of the subprograms is the development of an aero-thermodynamics model. The model will provide more realistic distributions of temperature and pressure or loads for safety/cost critical components from engine operational conditions and sensor readings. Furthermore, it will also provide an environment for the assessment of current and enhanced sensor suites and the prediction of degraded operation with wear/damage or control changes. With the required thermal flow information, structural and material analyses can be performed, and the remaining life of engine components can be assessed with confidence.

For technology development, a practical gas turbine combustor is selected as a research case. Gas turbine combustors are exposed to high-temperature, high-pressure, and high-dynamic load environments, and failures occasionally occur during operation. The flow parameters around and inside the combustor vary significantly, which causes considerably uneven structural stresses. Increased localized metal temperatures and thermal gradients can both reduce the combustor fatigue life. A higher temperature reduces the fatigue strength of the material, while a larger gradient increases the strain excursion and causes higher stresses. Therefore, for reliable structural, material and life analyses, the accurate definition of the working environment for the combustor is deemed necessary.

Due to the harsh conditions, experimental measurements inside the engine are extremely difficult. An alternative is to use validated computational flow dynamics (CFD) methods 


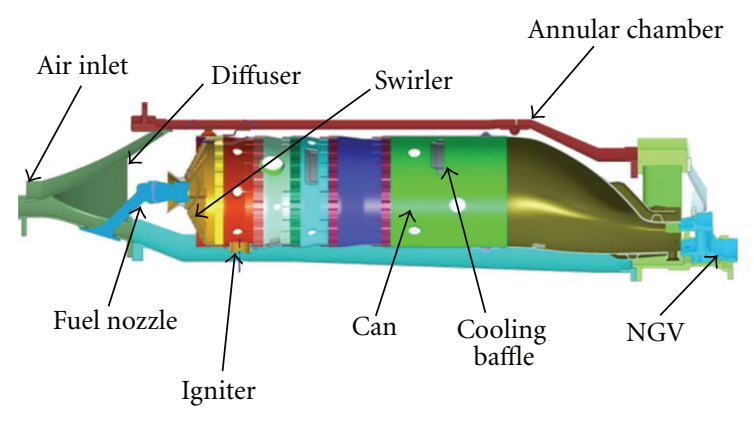

Figure 1: A 60-degree sector.

to document typical operating conditions and then correlate these detailed numerical results with the engine operating conditions and sensor readings to form semiempirical models. These models can be used for engine component life analysis or an essential component of CBM for engine fleet management.

This paper covers a high-fidelity CFD model of the gas turbine combustor, complex flow fields inside the combustor, temperature and pressure distributions over the combustor can as well as indications or suggestions from the present study.

\section{Thermal Fluid Dynamics Modeling of the Combustor}

\subsection{High-Fidelity CFD Model of the Combustor. Figure 1} illustrates a 60-degree sector of the gas turbine combustor. It is a can-annular design with six combustion cans and an annular air supply chamber [2]. Compressed air enters the annular chamber through a narrow annulus, decelerates in the diffuser, and then flows over and enters the combustor can or liner through air-management holes and cooling wiggle strips around the can. Inside the can, fine fuel droplets from a fuel nozzle evaporate, mix with air, and then burn. The mixture continues to react with air, cools down further downstream, and eventually reaches the air-cooled nozzle guide vanes (NGVs). For the present phase of work, the NGV is not included in the CFD model.

For traditional numerical simulations of gas turbine combustors, the computational domain is limited to the flow field inside the combustor liner, that is, the liner internal and external flow fields are decoupled. The airflow-splitting over the combustor liner is estimated based on semi-empirical discharge coefficient correlations $[3,4]$ and the flow rate is assumed evenly distributed over each liner airflow device (a row of holes, a wiggle strip, etc.). In the present study, both the liner internal and external flow fields are simulated simultaneously, that is, they are directly coupled.

Two engine operating conditions, takeoff and altitude cruise [2], are considered in the present study and the flow parameters for a single can are listed in Table 1.

2.2. Fuel Spray Measurements at the GTL High-Pressure Spray Rig. The temperature field in a combustor is dominated by
TABLE 1: Engine operating conditions.

\begin{tabular}{lcc}
\hline & Flow parameters & \\
\hline \multirow{3}{*}{ Takeoff } & Air inlet total pressure $(\mathrm{kPa})$ & 1000 \\
& Air mass flow rate $(\mathrm{kg} / \mathrm{s})$ & 2.36 \\
& Air inlet temperature $(\mathrm{K})$ & 606 \\
& Fuel mass flow rate $(\mathrm{kg} / \mathrm{s})$ & 0.053 \\
\hline \multirow{2}{*}{ Cruise } & Air inlet total pressure $(\mathrm{kPa})$ & 463 \\
& Air mass flow rate $(\mathrm{kg} / \mathrm{s})$ & 1.17 \\
& Air inlet temperature $(\mathrm{K})$ & 552 \\
& Fuel mass flow rate $(\mathrm{kg} / \mathrm{s})$ & 0.0207 \\
\hline
\end{tabular}

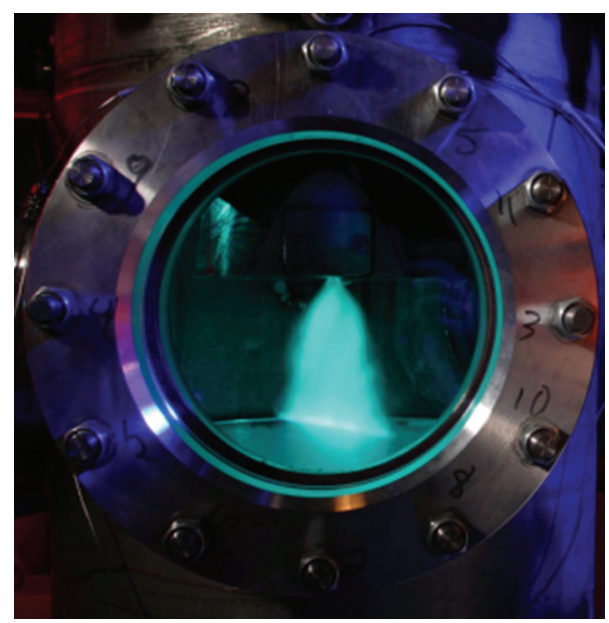

FIgURE 2: Fuel spray measurements in the GTL HPSR.

the fuel distribution and arrangement of primary, cooling and dilution air [5]. Therefore, it is essential to have proper fuel spray parameters in order to predict the combustor flow field accurately. The fuel spray characteristics were measured in the GTL (Gas Turbine Laboratory) High-Pressure Spray Rig (HPSR) with a phase Doppler particle analyzer (PDPA), as shown in Figure 2, at the engine cruise and takeoff conditions. Figure 3 gives a picture of the fuel spray in an air box which is the domed portion of the combustor can.

During spray measurement, the air and fuel flow rates remained the same as the flight conditions, and the pressure in the HPSR was adjusted to match the air density at flight. The measured parameters included the radial distributions of axial, tangential, and radial velocities, droplet size as well as fuel flux. All these results were used as the initial conditions of fuel spray for the predictions of the combustor thermal fields.

2.3. Mesh-Independent Studies and Combustor Mesh. Due to the geometrical complexity of practical gas turbine combustors, it is difficult to fully meet mesh-independence requirements. Researchers, such as [6], have pointed out that a gas turbine combustor simulation would need 410 million cells in order to claim mesh independence. This is understandable, for example, if the rollup of vortices along the bending jet and the structures of horseshoe and wake 


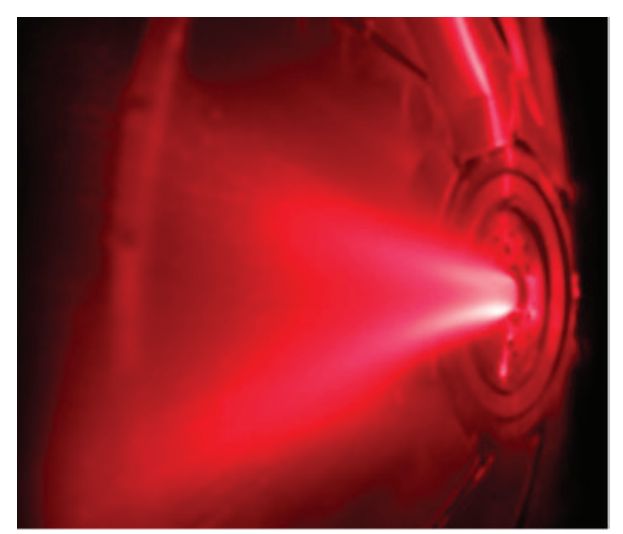

FIGURE 3: The fuel spray in a specifically built air box.

vortices for a single cross-flow jet [7] have to be properly resolved in numerical simulations, the required mesh size can be even larger than 410 million cells. Therefore, the best way to check mesh independence would be to examine if the objectives or required flow parameters remain meshindependent in simulations.

As mentioned before, the main objective of this work is to obtain accurate temperature and pressure distributions over the combustor can. Since the air distribution over the combustor can directly determines the combustor performance and metal wall temperature, the mesh-independence issues related to liner airflow devices (holes and wiggle strips) were studied first before meshing the whole 60-degree sector. For detail, please refer to $[8,9]$.

During meshing of the whole geometry, 36-84 surface elements were used for medium and large liner airflow holes. For small holes, such as the splashing holes over the dome swirler plates and cooling baffles (Figure 1), about 30 surface elements were generated. With these arrangements, the areaweighted numerical uncertainty of air distribution over the liner is less than $2 \%$.

For the whole combustor simulation, the wiggle strip was replaced by an equivalent slot which gave the same mass flow rate as that of the wiggle-strip for similar flow conditions. For the purpose of structure/material/life analyses of wiggle strips, the flow field of a single wiggle strip element was resolved with the boundary conditions obtained from the results of whole combustor simulations.

A few meshes were created and preliminary test runs were performed to improve the quality of numerical simulations. In the end, a mesh with 13.3 million cells was used for the simulations. Figure 4 illustrates the meshes of the 60-degree annular chamber (top) and the combustor can (bottom). Efforts were made to generate hexahedral cells as far as possible. Fine nodes were laid in and around holes, cooling slots, baffles, regions, dome swirler, and dome section. The nondimensional wall boundary parameter, $\mathrm{y}+$, at the combustor can walls varied from $\sim 20$ to $\sim 250$.

2.4. Flow Fields of the Combustor. A large amount of data is available to reveal complicated flow features and physical
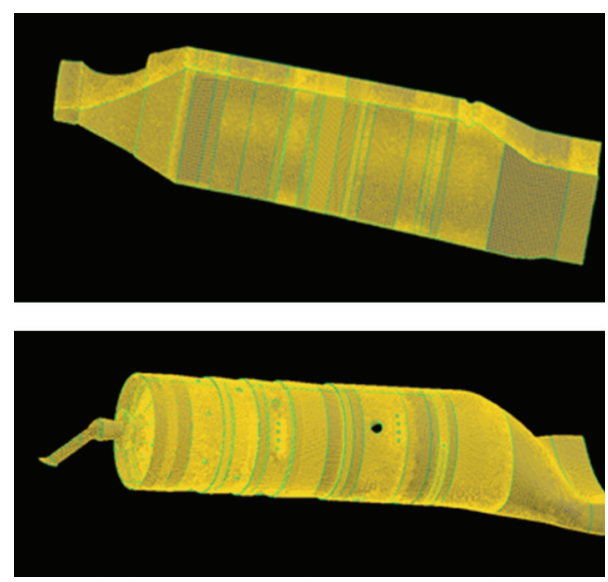

FIGURE 4: Meshes of 60-degree annular chamber and a combustor can.

phenomena inside the combustor [8]. Only some of the results at the cruise conditions are presented here. The flow features at takeoff are similar to those at cruise. Figures 57 show the velocity vectors and contours of Mach number and temperature along the middle longitudinal plane of the 60-degree sector of the combustor. In the figures, the thick black lines are the cut-through surfaces of the combustor can and fuel nozzle, and the dimensions and flow parameters are normalized by their representative values.

As shown in the upper plot of Figure 5, the compressed air flows into the annular chamber through a narrow inlet, slows down in the diffuser, and then enters the can dome through the splashing holes on the dome walls. As a result, two large recirculation zones are formed immediately downstream of the dome swirler, and the shape of the lower one is distorted by the igniter (Figure 1). These swirling flows are used to start and anchor flame in the combustor (Figure 7), and at the same time cool the dome head walls. Further downstream, the air flows through cooling slots into the combustion can, and the flow velocity gradually increases towards the can exit, as shown in both upper and lower plots of Figure 5. Another recirculation zone inside the can is also observed adjacent to the two dome recirculation regions. For the annular chamber, due to the geometrical blockage, strong swirling flows are found upstream of the dome, and a mild recirculation zone is observed in the dead flow region above the can exit section.

The Mach number contours at this section are given in Figure 6. In the primary zone of the combustor can (just downstream of the dome swirler), the Mach number or flow velocity is low. This gives enough time for fuel droplets to evaporate, mix and burn with air, and provides good environments for flame stabilization. The Mach number inside the can gradually increases downstream of the dome section and reaches a high value of $\sim 0.28$ at the can exit. In Figure 6, a maximum Mach number of 0.32 is observed in the diffuser due to the narrow flow passage (Figure 1). Shown in Figure 7 are the temperature contours inside and outside the can. As illustrated in Figures 5 and 6, the flow field is not symmetric, even in the upstream region of the 


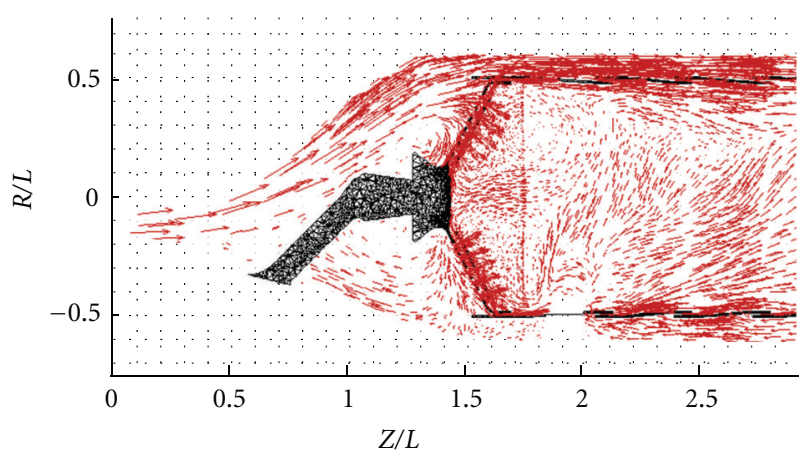

(a)

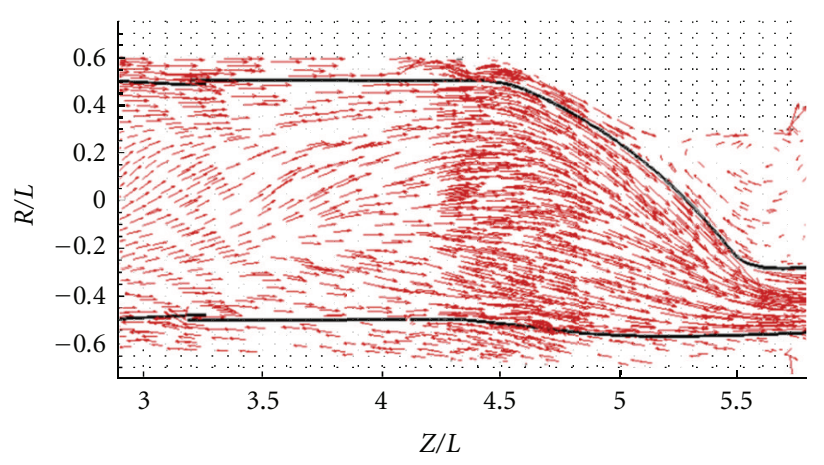

(b)

FIGURE 5: Velocity vector plots along the middle longitudinal plane.

combustor can. The high temperature region starts from the dome swirler and extends to the middle of the can with a maximum of $\sim 1$. This complies with gas turbine combustor design criteria [5], that is, the high-temperature region should be located in the primary and secondary zones. The low-temperature region in the center immediately downstream of the dome swirler is where the fuel spray is introduced into the flow field.

Figure 8 shows the velocity vector and Mach number plots, while Figure 9 illustrates temperature distribution at a dome swirler cross-section. This section cuts through the dome section, including swirler plates, splashing holes, and can liner wall, as indicated in thick white lines in Figures 8 and 9. There are eight swirler plates with 5 splashing holes for each, and only one hole for each plate is shown in the figures. As shown in Figure 8, the air enters the dome through small splashing holes and forms swirling flow at the plane perpendicular to the combustor axial axis. Referring to the two swirling regions inside the can observed along the longitudinal plane in Figure 5, it is understood that a donut-shaped vortex is formed immediately downstream of the dome swirler. Due to the geometric variation, high Mach number is found in the inner region of the annular chamber. The maximum temperature at this section (Figure 9) is close to that of the whole flow field (Figure 7), as shown in Figure 12, which could cause defects and cracks on the dome swirler [8].

The flow features at the cross-section of the second primary holes are given in Figures 10 and 11. Air enters

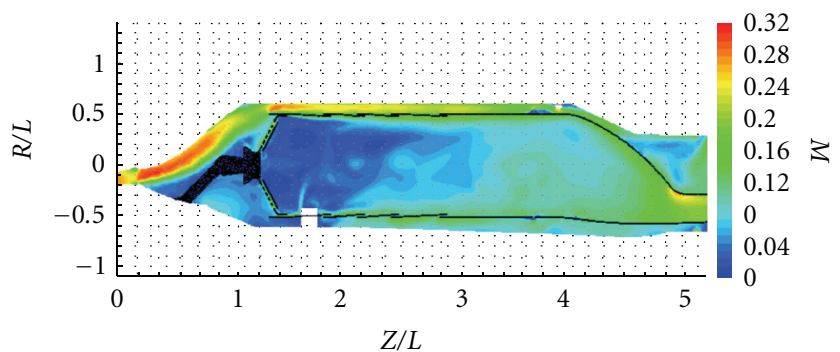

FIGURE 6: Mach number contours along the middle longitudinal plane.

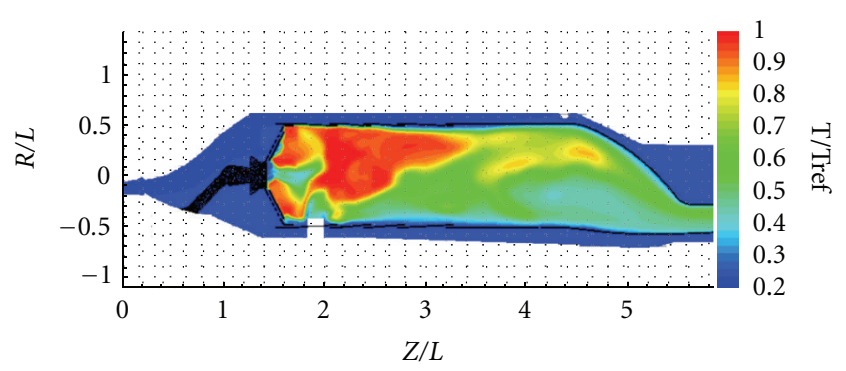

Figure 7: Temperature contours along the middle longitudinal plane.

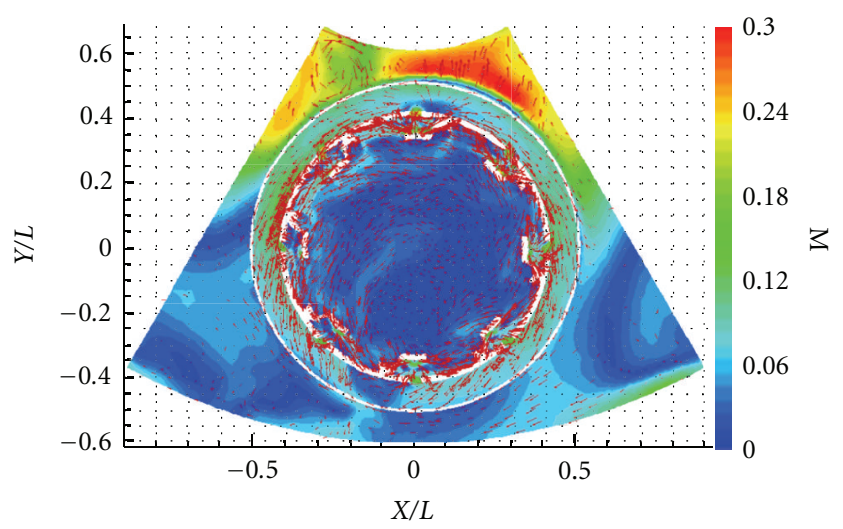

FIGURE 8: Velocity vectors and Mach numbers at a dome swirler cross-section.

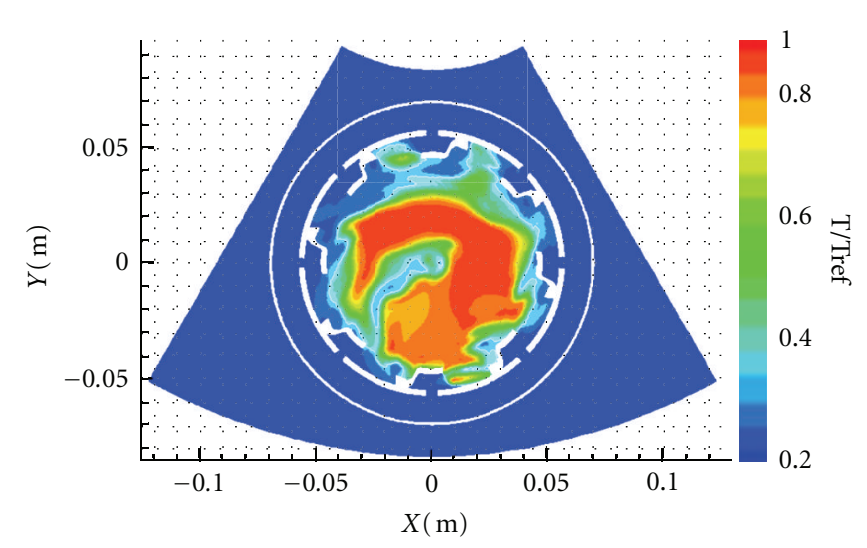

FIGURE 9: Temperature at a dome swirler cross-section. 


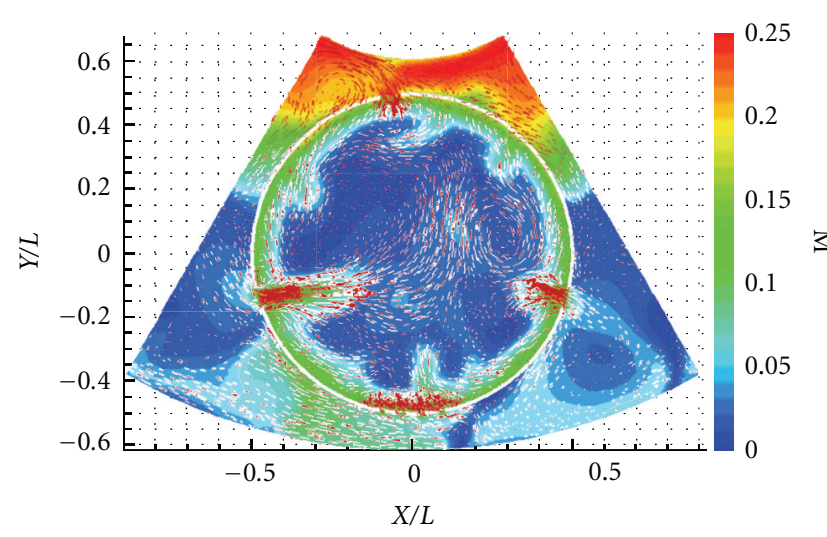

Figure 10: Velocity vectors and Mach numbers at the second primary hole section.

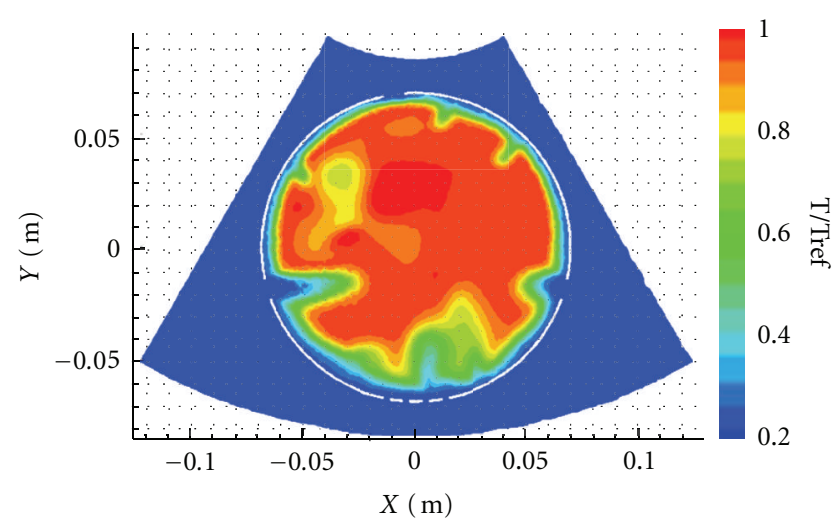

FIgURE 11: Temperature at the second primary hole cross-section.

the combustor can through 3 holes, and two large and two medium swirling regions are observed inside the can. It is important to note that although the size of the three air entry holes is the same, the airflow rate varies significantly, as shown in Figure 10. This is also observed at other liner air entry cross-sections (holes and wiggle strips), and the deviation of airflow rate can be as high as $\pm 25 \%$.

It is expected that the flow parameters such as flow and liner temperature distributions can be significantly different from those with the even airflow distribution over each cooling device in the traditional decoupled combustor simulations as mentioned earlier. As a result, the accuracy of combustor performance and life assessment can be considerably affected. This observation strongly suggests that for combustor simulations, the flow fields inside and outside the liner should be coupled in order to avoid potential prediction errors. At this primary zone section, the temperature is highest in the combustor flow field, as shown in Figure 11. This is because the combustion process takes place mainly in this zone. In Figures 10 and 11, a cooling baffle with four small splashing holes is displayed, and its cooling effect can be found in Figure 11.
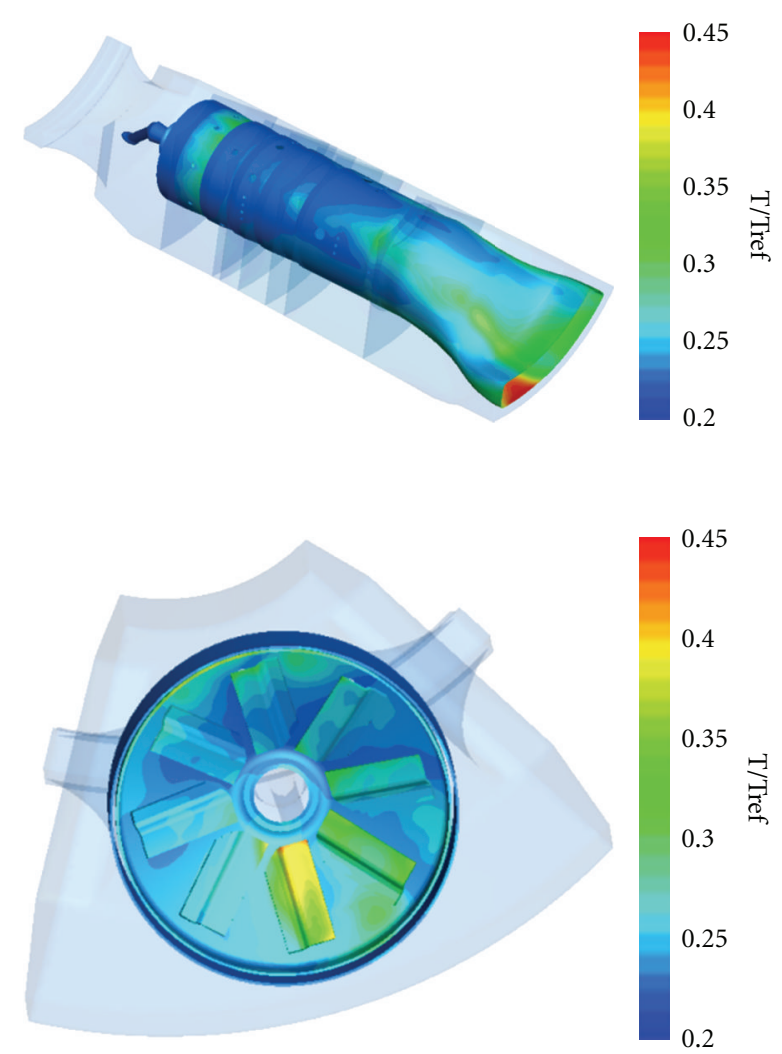

FIgURE 12: Combustor can and dome temperature contours at cruise.

2.5. Combustor Working Environment. Figures 12 and 13 present 3D temperature and absolute static pressure distributions over the combustor can and fuel nozzle at the cruise conditions. The maximum temperature occurs at the bottom left of the can exit. It reaches $\sim 0.50$, which is below but close to the allowable temperature for Hastelloy X alloy. As shown in Figure 12, the temperature over the combustor can vary significantly, which can cause considerably uneven structural stresses. As mentioned, increased localized metal temperatures and thermal gradients can both reduce the combustor fatigue life. Therefore, for reliable structural, material, and life analyses, the reliable working environments for engine components are deemed necessary.

The pressure distribution over the can walls is fairly uniform, as indicated in Figure 13. For the current combustor case, the pressure difference inside and outside the liner is minor, and therefore the pressure effect on the combustor life is probably insignificant in comparison with temperature. The detailed temperature distribution over the wiggle-strip element is illustrated in Figure 14 for cruise. The maximum temperature reaches $\sim 0.288$.

These detailed 3D temperature and pressure distributions over the combustor can and wiggle-strip element will be used for structural, material and life analyses of the combustor. It is expected that the critical or representative regions and/or parameters for the life analysis would be 


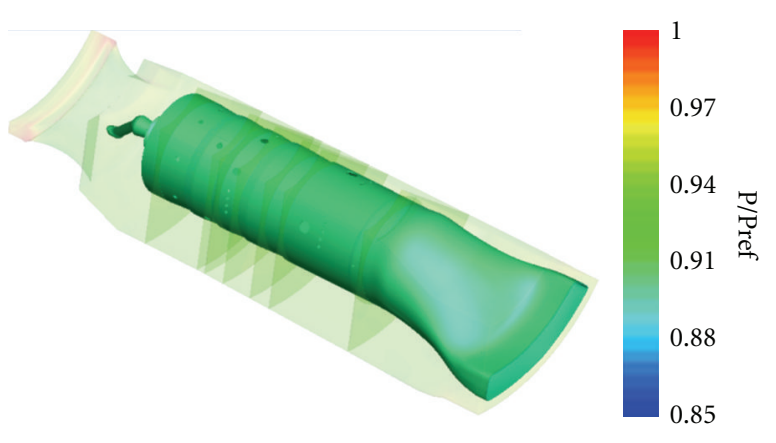

Figure 13: Combustor can pressure contours at cruise.

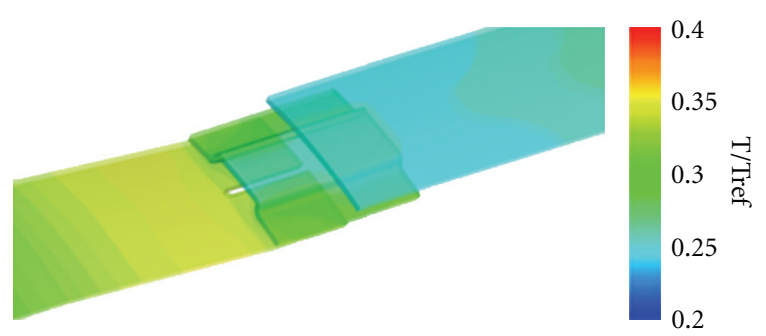

FIGURE 14: Temperature distribution over wiggle strip element at cruise.

identified, which may help the development of a simple aerothermodynamics model. This model should be able to correlate the engine operating conditions/sensor readings with the working environments of engine critical components.

\section{Conclusions and Future Work}

To be able to reduce the cost of gas turbine engine fleet management, extend their service time, and perform maintenance actions only when they are required, it is vital to provide reliable aero-thermodynamic loads for the engine critical components.

As a first phase of the development of an aero-thermodynamics model, the benchmark modeling on a practical gas turbine combustor is successfully carried out, and the two-phase, steady, turbulent, compressible, reacting flow fields at the cruise and takeoff conditions are obtained. The complicated flow features inside the combustor are observed. More importantly, the present study indicates that the airflow over each liner flow device is not evenly distributed, and $\pm 25 \%$ variations around the average values are observed. These findings suggest that the coupled combustor simulation should be performed.

The detailed 3D temperature and pressure distributions over the combustor can and wiggle-strip element at the engine cruise and takeoff conditions are available for structural, material, and life analyses. It is expected that the critical or representative regions and/or parameters would be identified for the development of a simple aerothermodynamics model, which can correlate the engine operating conditions/sensor readings with the working environments of engine critical components.
The present study also indicates that it is necessary to carry out a further systematic study in order to develop an adequate aero-thermodynamics model. The on-going and future activities should include validation of numerical results, simulations at typical engine operating conditions, and development of simple correlations between engine operating conditions and component working environments.

\section{Acknowledgments}

The authors are grateful to the Department of National Defence and the Canadian Forces as well as the National Research Council Gas Turbine Laboratory for funding and supporting this collaborative research project. The technical authorities and project managers at DND and NRC, Mr. Ken McRae and Mr. Jeff Bird, respectively are gratefully acknowledged.

\section{References}

[1] J. Bird, M. Mrad, X. Wu, and C. Yang, "Propulsion System Mission and Maintenance Planning Demonstrator," LTR-GTL2010-0092, The National Research Council of Canada.

[2] V. L. Oechsle, P. T. Ross, and H. C. Mongia, "High density fuel effects on gas turbine engines," Tech. Rep. AIAA-87-1829, San Diego, Calif, USA, 1987, AIAA/SAE/ASME/ASEE 23rd Joint Propulsion Conference.

[3] P. J. Stuttaford and P. A. Rubini, "Preliminary gas turbine combustor design using a network approach," Journal of Engineering for Gas Turbines and Power, vol. 119, no. 3, pp. 546-552, 1997.

[4] R. C. Adkins and D. Gueroui, "An improved method for accurate prediction of mass flows through combustor liner holes," Tech. Rep. GT86-149, Duesseldorf, Germany, 1986.

[5] A. H. Lefebvre and D. R. Ballal, Gas Turbine Combustion, Taylor and Francis Group, 2010.

[6] H. C. Mongia, "Recent advances in the development of combustor design tools," Tech. Rep. AIAA-2003-4495, Huntsville Alabama USA, 2003, AIAA/SAE/ASME/ASEE 39th Joint Propulsion Conference.

[7] M. Samimy, K. S. Breuer, L. G. Leal, and P. H. Steen, A Gallery of Fluid Motion, Cambridge University Press, Cambridge, UK, 2003.

[8] L. Y. Jiang and A. Corber, "Benchmark Modeling of T56 Gas Turbine Combustor-phase I, CFD model, flow features, air distribution and combustor can temperature distribution," LTR-GTL-2010-0088, The National Research Council of Canada, 2011.

[9] L. Jiang, "Combustor cooling wiggle strip and geometrical simplification," in Proceedings of the International Mechanical Engineering Congress and Exposition (IMECE '08), pp. 177-184, November 2008. 

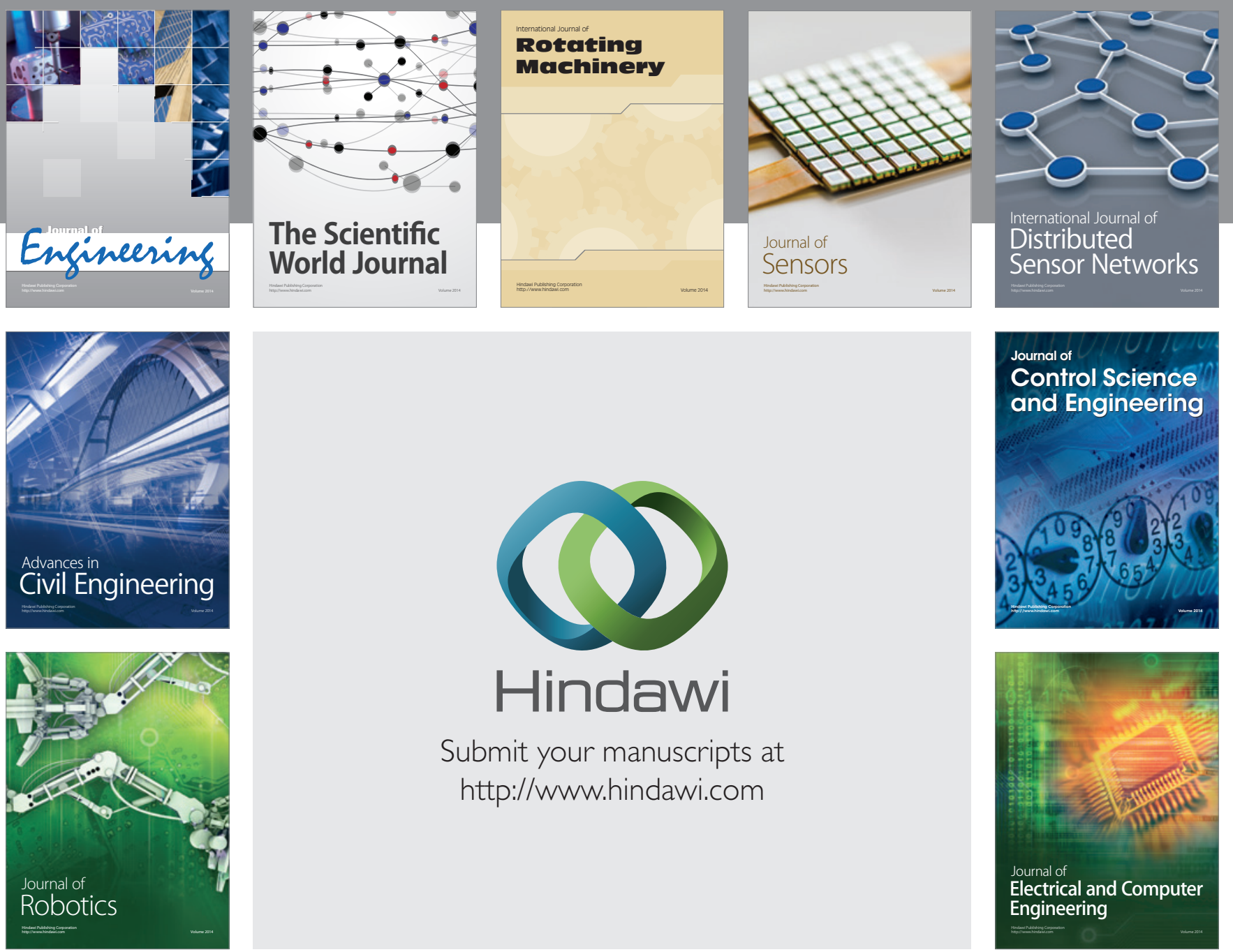

Submit your manuscripts at

http://www.hindawi.com
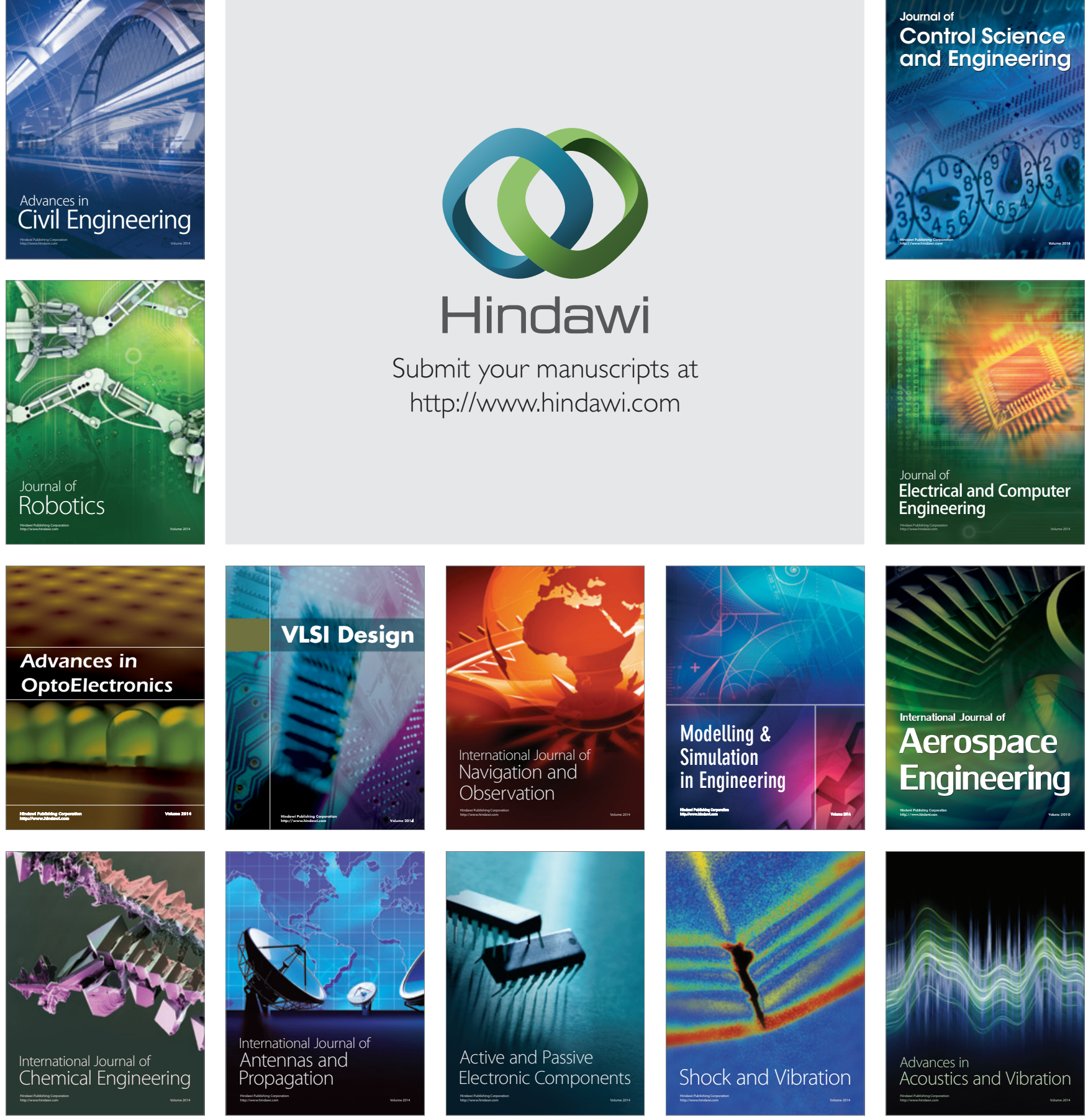